\title{
Numerical Analysis of Suction/Blowing on MHD Viscousnanofluid Flow over Stretched Surface with Velocity and Thermal Slip Conditions
}

\author{
A Tuama Alomai ${ }^{1}$, M Muhamad ${ }^{1}$, Mohammed M Fayyadh ${ }^{1, *}$, Hayder R. Jasim ${ }^{1}$, Hasan Shaheed ${ }^{2}$, \\ Mohammed Hakim ${ }^{3}$, Ali A Abdulridha ${ }^{1}$ \\ ${ }^{1}$ Research Centre for Computational Fluid Dynamics, Faculty of applied Sciences \& Technology, \\ University Tun Hussein Onn Malaysia, Malaysia \\ ${ }^{2}$ Faculty of Civil and Environmental Engineering, University Tun Hussein Onn Malaysia, Malaysia \\ ${ }^{3}$ Faculty of Mechanical and Manufacturing Engineering, University Tun Hussein Onn Malaysia, Malaysia
}

Received July 30, 2019; Revised October 1, 2019; Accepted December 27, 2019

Copyright $\odot 2019$ by authors, all rights reserved. Authors agree that this article remains permanently open access under the terms of the Creative Commons Attribution License 4.0 International License

\begin{abstract}
This paper studied the effects of suction/blowing parameters of magnetohydrodynamic (MHD) nanofluid's viscous flow over an exponentially stretching sheet. In this work, nanofluid flow of water-based copper was considered as a nanoparticle. The radiation parameters, velocity and thermal slip constraint, and magnetic field were applied in similarity transformations to solve the nonlinear ordinary differential equations (ODEs) approximately by reducing the nonlinear partial differential equations (PDEs). The obtained numerical results of velocity and temperature against different values of suction/blowing parameters with varying profiles were displayed and analyzed by using Maple 18 software based on the fourth-fifth order Runge-Kutta Fehlberg technique with shooting method. The dimensionless Velocity decreased with the increasing magnetic field, suction/blowing, and thermal slip condition parameters. Whereas, the profiles of temperature intensified with the growing magnetic field, velocity slip and thermal radiation parameters. Finally, in the experiment, the effect of increased velocity and thermal slip parameters in general caused decrease in the heat transfer with base fluid, but in case of nanofluid this impact was lesser. Alternatively, it can be stated that the effect of suction/blowing parameter caused a decrease and then an increase in the heat transfer.
\end{abstract}

Keywords Heat Transfer, Velocity and Thermal Slip Conditions, Radiation Parameter and Suction/Blowing Parameter

\section{Introduction}

Nanotechnology is the suspension of nanomaterials or nanoparticles in base liquids (or base fluids) such as water, ethylene glycol and oil, these particles taken from solid of materials with a high thermal conductivity such as copper, copper oxide, aluminium, titanium, etc. These base liquids are low in transferring heat because of the low thermal conductivity at them, and because of the importance of the uses of these fluids, scientists were interested in developing a method to make these fluids with high thermal conductivity in different rate according to the nature of these fluids.

Nanotechnology or nano-fluids are multidisciplinary and have many applications in our life and industries where they are divided into two types of Newtonian fluids, which are liquids with low viscosity where the viscosity is proportional to the flow rate in a linear such as water and non-Newtonian manner where the change between viscosity and the flow rate is nonlinear and in many cases depends on Time to change that nature of substance, such as dyes, ketchup, Blood and concrete. Choi et al. [1] is the first scientist to use nanoparticles in base liquids by analysing the heat transfer process using the boundary layer approximation. Two recurrent models were used by researchers in analysing the approximation of the boundary layer and in heat transfer [2,3]. Tiwari-Das[4] technique was concerned with the density, viscosity, and nanoparticle volume fraction and J. Buongiorno [5] technique analysed the effects of Brownian motion and thermophoresis mainly to suspend nanoparticles.

Our study adopts Tiwari Das model, which focuses on the viscosity density, size and shape of the nanoparticle, 
because these characteristics are important in enhancing heat transfer. As the suspension of the molecule in the liquid and as a result of the adhesion of this part to the surface, the process of heat transfer between the surface and the liquid is enhanced and vice versa.[6]. One of the major assumptions in the Navier-Stokes equations is the topic of the boundary no-slip condition. But sometimes this condition is not fulfilled, as in special cases we use slip or partial slip velocity on an extended surface, as happens in the emulsion of paint, polymer solutions and soaps or foam. Slip velocity is a phenomenon that occurs when the fluid or particles do not stick to the solid surface, thus the velocity at the solid surface is not zero, moreover the investigation of considering boundary conditions[7]. Therefore, slipconditions are used in many important technological applications such as polymer melt, artificial polishing, internal cavities and heart valves. Furthermore, in many cases, we cannot neglect the importance of the effect of slip, especially in the uses of sliding surfaces in engineering, which relates to lubrication[8]. The heat transfer analysis of nanofluids under the local thermal non equilibrium condition shows fluids exhibiting slip are important in technological applications[9]. Daniel et al. [10] analysed the slip conditions on nonlinear stretching and shrinking in porous medium. Furthermore, they investigated the effects of velocity slip of MHD two dimensional nanofluid flow on temperature and concentration convective boundary conditions in the presence of electrical and magnetic field. Dhanai et al. [11] explored the impact of Brownian motion and thermophoresis and dissipation of viscous with mixed convection slip nanofluid flow, and as well as studied the uniformly conducting flow past and inclined cylinder surface. In this paper, the rate of heat and mass transfer is enhanced with parameters except the slip velocity parameter.

Khan et al.[12] is concerned with the chemical reaction for Carreau nanofluid model past a wedge surface. The heat and mass transfer was investigated by examining the impact of thermal and slutal slips surface as well as the effect of variable thermal conductivity. The study was showing the computations in nanoparticle concentration of the chemical reaction were clear to be a decreasing function of Schmidt number and solutal slip parameter. Mabood et al. [13] analysed the numerical study of the effect of thermal radiation and velocity-thermal slips parameters in MHD nanofluid flow over a permeable stretching surface. This study was examined by Homotopy analysis method in which the skin friction and local Nusselt number was investigated. The study shows that the skin friction increases with suction/injection parameter and decreases with velocity slip parameter. The local Nusselt Number decreases with magnetic parameter, radiation, velocity slip and thermal slip. Mahanthesh et al. [14] investigated three-dimensional of slip flow in the presence of water-based nanoparticle with temperature boundary condition. The study is numerical analysis to examine the effect of such parameter and to solve the nonlinear differential equation by using shooting technique.

Numerical study for boundary layer nanofluid flow over permeable stretched surface in the presence of magnetic effect is investigated by Ibrahim et al. [15] The problem is solved using Runge-Kutta (45-order) with the aid of shooting technique to evaluate the effect of slip boundary condition and thermal radiation on nanofluid flow.

Many researchers investigated the slip conditions with various models and used numerical or analytical methods to get the resetting [16-22]. When heat is transferred by electromagnetic waves such as radio waves, $\mathrm{x}$-rays, infrared wave and visible light, it is known as radiation. All the objects emit and as well absorb the radiant energy including human bodies.

But some material and substances are much better than others in case of thermal conductivity. These materials that are good at emitting radiant energy are also very good at absorbing it, for example sun. However, in case of radiation, most of the heat produced in earth comes from the earth itself[23]. The radiant energy emitted by the earth is called the terrestrial radiation[24]. Gases in the atmosphere trap the terrestrial radiation on the earth and keep it warm. Unlike conduction and convection, radiation happens even when there is no material for the heat to travel through, for instance sun. Recently, many works have been carried out on the heat transfer magneto hydrodynamics (MHD), as can be seen in [25, 26], [27].

The aim of this work is investigating the effect of slip conditions parameters of surface on the heat transfer. This article uses Tiwari-Das model of nanofluid flow to analyse the effect of thermo-properties of nanofluid (using water-copper) such as density, viscosity and nanoparticle volume fraction. The mechanisms of thermal conductivity enhancement by different parameter such as radiation, magnetic field and suction/blowing are discussed. The governing partial differential equations are transformed into nonlinear ordinary differential equations by a similarity transformation. The effects of some governing parameters of nanofluids flow and heat transfer characteristics are graphically presented and discussed. It also examines the accuracy of such numerical methods which are Runge-Kutta Fehlberg with shooting technique in Maple 18. The accuracy of this work in the submitted paper confirms the development of a comparison with previous results in the literature that define an important path in carrying out the numerical technique. The main focus of this paper is to investigate the procedure of implementing the nonlinear differential equations for the steady boundary layer MHD viscous nanofluid's (water as a base fluid and nanoparticle copper) flow and radiative heat transfer over a stretched surface and tabulate the results of the experiment.

\section{Mathematical Formulation}

In this paper, we considered a steady two-dimensional 
incompressible viscous magneto-hydrodynamics (MHD) flow and used nanofluid as a liquid which was namely water-copper past stretching sheet. The x-axis was taken along the stretched surface in the direction of the movement, while y-axis was perpendicular to it. The flow was proposed to be generated by stretching surface from a slit with such a big force that the velocity of the boundary sheet was an exponential order of the directional flow of $\mathrm{x}$ coordinate. $B(x)=B_{o} e^{x / 2 l}$ was a variable magnetic field that was applied normal to the sheet. The physical look of the flow's configuration with the system coordinate is given in Figure 1.

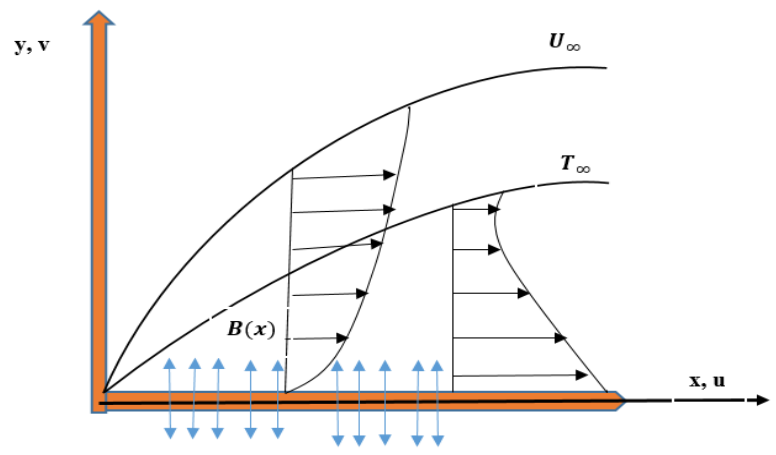

Figure 1. Schematic of a stretching sheet with magnetic field

A proposed governing equation was followed in[28].

$$
\begin{gathered}
\frac{\partial u}{\partial x}+\frac{\partial v}{\partial y}=0 \\
u \frac{\partial u}{\partial x}+v \frac{\partial u}{\partial y}=v_{n f} \frac{\partial^{2} u}{\partial y^{2}}-\frac{\sigma_{n f} B_{0}^{2}}{\rho_{n f}} u \\
u \frac{\partial T}{\partial x}+v \frac{\partial T}{\partial y}=\frac{k_{n f}}{\left(\rho C_{p}\right)_{n f}} \frac{\partial^{2} T}{\partial y^{2}}-\frac{\partial q_{r}}{\partial y}
\end{gathered}
$$

By means of Roseland approximation for radiation: $q_{r}=-\frac{4 \delta^{*}}{3 k^{*}} \frac{\partial T^{4}}{\partial y}$, where $\delta^{*}$ is the Stefan Boltzman constant and $k^{*}$ is the absorption coefficient. Suppose that $T^{4}$ is a linear function of temperature then equation (3) becomes:

$$
u \frac{\partial T}{\partial x}+v \frac{\partial T}{\partial y}=\frac{k_{n f}}{\left(\rho C_{p}\right)_{n f}} \frac{\partial^{2} T}{\partial y^{2}}+\frac{16 \delta^{*} T_{\infty}^{3}}{3\left(\rho C_{p}\right)_{n f} k^{*}} \frac{\partial^{2} T}{\partial y^{2}},
$$

where, $\mathrm{u}$ and $\mathrm{v}$ denote the velocity of the components in $\mathrm{x}$ and y direction respectively, $v_{n f}=\left(\mu_{n f} / \rho_{n f}\right)$ denotes the operational nano-liquids' kinematic viscosity, $\mu_{n f}$ denotes the nano-liquids' dynamic viscosity, $\rho_{n f}$ represents the nano-liquids' density, $\mathrm{T}$ denotes temperature, , $\sigma_{n f}$ denotes nano-liquids' electrical conductivity, $B_{o}$ signifies uniform magnetic field strength, $\alpha_{n f}=\left(k_{n f} /\left(\rho C_{p}\right)_{n f}\right)$ indicates nano-liquids' thermal diffusivity, $k_{n f}$ means nanofluid's thermal conductivity, and $\left(\rho C_{p}\right)_{n f}$ stands for nano-liquids' functional heat capacity, defined as[29]:

$$
\begin{aligned}
& \mu_{n f}=\frac{\mu_{b f}}{(1-\xi)^{2.5}}, \quad \alpha_{n f}=\frac{k_{n f}}{\left(\rho C_{p}\right)_{n f}}, \quad\left(\rho C_{p}\right)_{n f}=(1-\xi)\left(\rho C_{p}\right)_{b f}+\xi\left(\rho C_{p}\right)_{s}, \\
& \rho_{n f}=(1-\xi) \rho_{b f}+\xi \rho_{s}, \quad \frac{k_{n f}}{k_{b f}}=\frac{\left(k_{s}+(1-m) k_{b f}\right)-(1-m) \xi\left(k_{b f}-k_{s}\right)}{\left(k_{s}+(1-m) k_{b f}\right)+\xi\left(k_{b f}-k_{s}\right)}, \\
& \sigma_{n f}=\left(1+\frac{3\left(\frac{\sigma_{s}}{\sigma_{b f}}-1\right) \xi}{\left(\frac{\sigma_{s}}{\sigma_{b f}}+2\right)-\left(\frac{\sigma_{s}}{\sigma_{b f}}-1\right) \xi}\right)
\end{aligned}
$$

Along with the initial/boundary conditions;

$$
\begin{aligned}
& u=U_{o} e^{x / l}+N_{o} e^{-x / 2 l} v_{n f} \frac{\partial u}{\partial y}, v=-V_{o} e^{-x / 2 l}, \\
& T=T_{\infty}+T_{o} e^{-x / 2 l}+D_{o} e^{-x / 2 l} v_{n f} \frac{\partial T}{\partial y} ; y=0 \\
& u \rightarrow 0, T \rightarrow T_{\infty} ; y \rightarrow \infty
\end{aligned}
$$

Where $U_{o}$ is the reference velocity, $N_{o}$ is the initial value of velocity slip condition, $V_{o}$ is the initial value of suction $\left.V_{o}\right\rangle 0$ or blowing $V_{o}\left\langle 0, T_{\infty}\right.$ is the temperature at far and as well as the temperature away from the palate, $\mathrm{L}$ is a constant, and $D_{o}$ is the thermal slip factor's initial value. The similarity variables considered in the report were:

$$
\eta=\sqrt{\frac{U_{o}}{2 v l}} e^{x / 2 l} y, \theta(\eta)=\frac{T-T_{\infty}}{T_{o}} e^{-x / 2 l}
$$

The Local Rayleigh number and the stream function, $\psi$ are given below respectively:

$$
u=U_{o} e^{x / l} f^{\prime}(\eta), v=-\sqrt{\frac{v_{o}}{2 l}} e^{x / 2 l}\left[f(\eta)+\eta f^{\prime}(\eta)\right]
$$

However, the momentum and energy equations can be transformed into the corresponding differential equations by using similarity transformation Eques. (7), (8);

$$
\eta=\sqrt{\frac{U_{o}}{2 v l}} e^{x / 2 l} y \text { where, } \delta=D_{o} \sqrt{\frac{U_{o}}{2 v l}} \text { is the thermal }
$$


slip, $\operatorname{Pr}=\frac{\mu C_{p}}{k}$ is the Prandtl number, $\lambda=N_{o} \sqrt{\frac{v U_{o}}{2 l}}$ is the velocity slip, $M=\sqrt{\frac{2 \sigma B_{O}^{2}}{\rho U_{0}}}$ is represented as the magnetic parameter, and $S=V_{o} \sqrt{\frac{2 l}{U_{O}}}$ is the suction parameter, $\left.V_{o}\right\rangle 0$ or blowing $V_{o}\langle 0$.

By the time, we substituted the similarity transformations and hence, the above equations took the form

$$
\begin{aligned}
& f^{\prime \prime \prime}(\eta)+f^{\prime \prime}(\eta) f(\eta)-2\left(f^{\prime}(\eta)\right)^{2}-A_{2} M^{2} f^{\prime}(\eta)=0 \\
& \left(1+\frac{4}{3}\left(\frac{k_{f}}{k_{n f}}\right) R\right) \theta^{\prime \prime}(\eta)+A_{1} \cdot \operatorname{Pr}\left(\eta \cdot f(\eta) \cdot \theta^{\prime}(\eta)-f^{\prime}(\eta) \cdot \theta(\eta)\right)=0
\end{aligned}
$$

Both the initial and boundary conditions in equation (6) were also respectively transformed in ODEs form as given below:

$$
\begin{aligned}
& f(0)=S, f^{\prime}(0)=1+A_{3} \lambda f^{\prime \prime}(0), \theta(0)=1+A_{4} \delta \theta^{\prime}(0) \\
& f^{\prime}(\infty)=0, \theta(\infty)=0
\end{aligned}
$$

here $R=\frac{4 \delta^{*} T_{\infty}^{3}}{k k^{*}}$ denotes the radiation parameter, and

$$
\begin{aligned}
& A_{1}=\frac{1}{(1-\xi)^{2.5}\left(1-\xi+\xi\left(\frac{\rho C_{p}}{\rho C_{f}}\right)\right)}, \\
& A_{2}=\left(1+\frac{3\left(\frac{\sigma_{s}}{\sigma_{f}}-1\right) \xi}{\left(\frac{\sigma_{s}}{\sigma_{f}}+2\right)-\left(\frac{\sigma_{s}}{\sigma_{f}}-1\right) \xi}\right)\left(\frac{1}{\left(1-\xi+\xi\left(\frac{\rho_{s}}{\rho_{f}}\right)\right)}\right), \\
& A_{3}=\sqrt{\frac{1}{(1-\xi)^{2.5}\left(1-\xi+\xi\left(\frac{\rho_{S}}{\rho_{f}}\right)\right)}},
\end{aligned}
$$$$
A_{4}=\sqrt{(1-\xi)^{2.5}\left(1-\xi+\xi\left(\frac{\rho_{s}}{\rho_{f}}\right)\right)}
$$

The transformations (5) and (11) above are related to the solid particles-water in table 2 .

\section{Numerical Approach and Validation}

The partial differential equations (2-3) in this paper are converted into ordinary equations after applying the self- similar transformation. On the other hand, the governing equations (9) have a high degree of nonlinearity and are difficult to solve by the usual analytical solution. In addition, this system is completed by describing the physical phenomena by adding the boundary conditions (10). Therefore, the system should be solved by numerical methods, and there are a lot of numerical methods for the numerical solution, but we choose the Runge-Kutta of order (45) method with the aid of shooting technique, and the characteristic of this method is that it solves the boundary value problems [30]. In the beginning, the issue of the boundary value problems is converted to the initial value problems, and thus the equations (9) become, which (velocity and energy are of the third and second degree respectively), and therefore the sum of their degree together becomes seven. To find the calculation for these equations using the Runge-Kutta Fehlberg of order (45) method, it must convert these equations into a first-order system through (12);

$$
f=y_{1}, f^{\prime}=y_{2}, f^{\prime \prime}=y_{3}, \theta=y_{4}, \theta^{\prime}=y_{5}
$$

And then this new system led to:

$$
\left[\begin{array}{l}
y_{1}^{\prime} \\
y_{2} \\
y_{3} \\
y_{4} \\
y_{5}
\end{array}\right]=\left[\begin{array}{l}
1+A_{3} \lambda y_{3} \\
x_{1} \\
-y_{3} y_{1}+2 y_{2}^{2}+A_{2} M^{2} y_{2} \\
x_{2} \\
\frac{-A_{1} \operatorname{Pr} y_{5} y_{1}+y_{2} y_{4}}{\left(1+\frac{3}{4}\left(\frac{k_{f}}{k_{n f}}\right) R\right)}
\end{array}\right]
$$

And for clarification, the initial conditions are not defined at infinity, while boundary conditions are described for infinity, so we use these boundary conditions to generate two un-defined initial conditions.

Now the unknown initial conditions are guessed $\left.\left(\left[\chi_{1}, \chi_{2}\right]=\right]=\left[f^{\prime \prime}(0), \theta^{\prime}(0)\right]\right)$, and the boundary conditions are converted to initial conditions through (13) where,

$$
\left[\begin{array}{l}
y_{1}(0) \\
y_{2}(0) \\
y_{3}(0) \\
y_{4}(0) \\
y_{5}(0)
\end{array}\right]=\left[\begin{array}{l}
s \\
1+A_{3} \lambda y_{3} \\
\chi_{1} \\
1+A_{4} \delta y_{5} \\
\chi_{2}
\end{array}\right]
$$

After completing the initial and boundary conditions, Runge- Kutta Fehlberg method uses to find an approximate solution through the formula of Runge- Kutta Fehlberg method, which is; 
$K_{0}=f\left(x_{n}+y_{n}\right)$,

$K_{1}=f\left(x_{n}+1 / 4 h, y_{n}+1 / 4 h K_{0}\right)$.

$K_{2}=f\left(x_{n}+3 / 8 h, y_{n}+3 / 32 K_{0} h+9 / 32 K_{1} h\right)$,

$K_{3}=f\left(x_{n}+12 / 13 h, y_{n}+1932 / 2197 K_{0} h-7200 / 2197 K_{1} h+7296 / 2197 K_{2} h\right)$,

$K_{4}=f\left(x_{n}+h, y_{n}+439 / 216 K_{0} h-8 K_{1} h+3860 / 513 K_{2} h-845 / 4104 K_{3} h\right)$,

$K_{5}=f\left(x_{n}+1 / 2 h, y_{n}-8 / 27 K_{0} h+2 K_{1} h-3544 / 2565 K_{2} h+1859 / 4104 K_{3} h-11 / 40 K_{4} h\right)$

$y_{n+1}=y_{n}+25 / 216 K_{0}+1408 / 2565 K_{2}+2197 / 4104 K_{3}-1 / 5 K_{4}$

$z_{n+1}=z_{n}+16 / 135 K_{0}+6656 / 12825 K_{2}+28561 / 56430 K_{3}-9 / 50 K_{4}+2 / 55 K_{5}$

Where $y$ represents the fourth degree and $\mathrm{z}$ represents the fifth degree. The determination of the error is by assigning the difference to the degrees $\mathrm{z}$ and $\mathrm{y}$. If the error exceeds the threshold limit, the results can be recalculated using a small step size $h$. The method for estimating a small step size $\mathrm{h}$ is calculated by equation 17 . These procedures continue until the convergence criteria are met.

$$
h_{\text {new }}=h_{\text {old }}\left[\frac{\varepsilon h_{\text {old }}}{z_{n+1}-y_{n+1}}\right]^{1 / 4}
$$

The values of the heat transfer coefficient $-\theta^{\prime}(0)$ and the skin-friction coefficient $f$ "(0) were very important for this method. The experimental results were obtained against different values of Prandtl number $(\mathrm{Pr})$ keeping $\lambda=0, M=0$, and $\delta=0$ and they were compared with the available results of Ishak [31] and Mukhopadhyay [32]. It was observed that the results were in an acceptable range in table 1 .

\section{Results and Discussion}

A numerical analysis was done to find out the MHD viscous flow and radiative heat transfer at the steady boundary layer over an exponentially stretched sheet.

In this study, various values of the magnetic, radiation, velocity and thermal slip conditions, and suction/blowing parameters were numerically executed for governing equations (ODEs) along with the boundary conditions in equations (10), [14-16].

Fig.2 (a, b) shows the effect of magnetic field parameter with suction/blowing parameter. It is clear that the velocity, as can be found in fig.2 (a), is considerably reduced with the increase in $M$. On the other hand, the temperature dimensionless increases with increasing magnetic field, as depicted in fig. 2 (b). In these cases, the velocity disappears at relatively large distance from the plate.

Table 1. Comparison of the rate of heat transfer $-\theta^{\prime}(0)$ obtained against several values of Prandtl number parameter in the absence of velocity and thermal slips and suction/blowing in the experiment with the same found by Ishak [31] and Mukhopadhyay[32]

\begin{tabular}{|c|c|c|c|c|c|}
\hline $\mathrm{R}$ & $\mathrm{M}$ & $\mathrm{Pr}$ & Ishak & Mukhopadhyay & Present work \\
\hline 0.0 & 0.0 & 1.0 & 0.9548 & 0.9547 & 0.9548 \\
\hline & & 2.0 & 1.4715 & 1.4714 & 1.4714 \\
\hline & & 3.0 & 1.8691 & 1.8691 & 1.8690 \\
\hline & & 5.0 & 2.5001 & 2.5001 & 2.5001 \\
\hline & & 10.0 & 3.6604 & 3.6603 & 3.6603 \\
\hline
\end{tabular}

Table 2. Thermos-physical properties of water and nanoparticle Copper

\begin{tabular}{|c|c|c|c|c|c|}
\hline & $\rho\left(k g / m^{2}\right)$ & $c_{p}(J k g k)$ & $K(W / m k)$ & $\sigma\left(\Omega^{-1} m^{-1}\right)$ & $5^{\text {Prandtl number }}$ \\
\hline Pure water & 997.1 & 4179 & 0.613 & 6.82 \\
\hline Copper $(\mathrm{Cu})$ & 8933 & 385 & 401 & $59.0^{*} 10^{0}$ & - \\
\hline
\end{tabular}




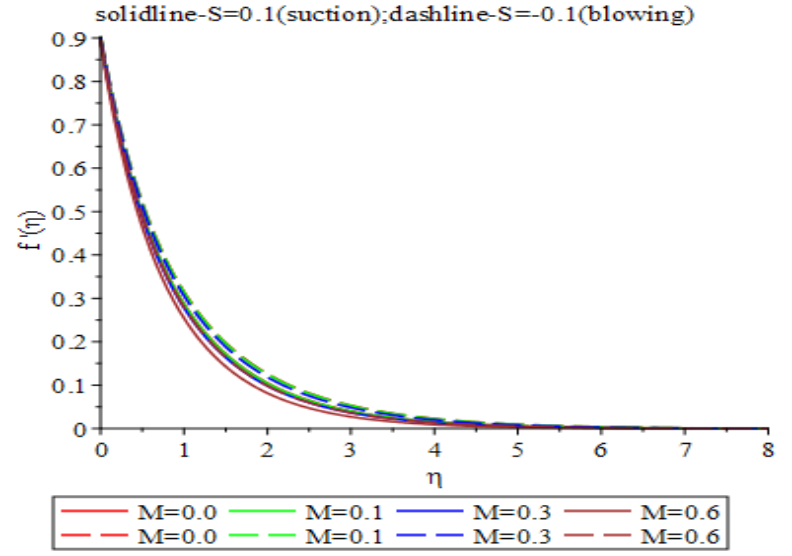

(a)

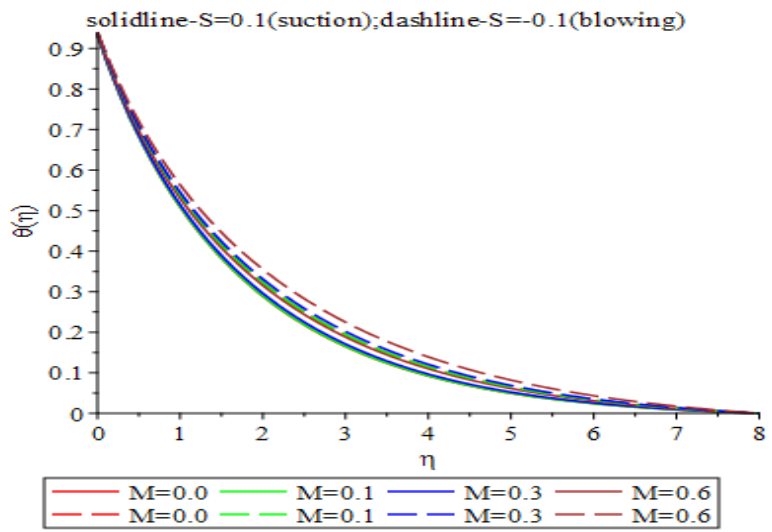

(b)

Figure 2. The effect of magnetic field parameter vs velocity and temperature dimensionless

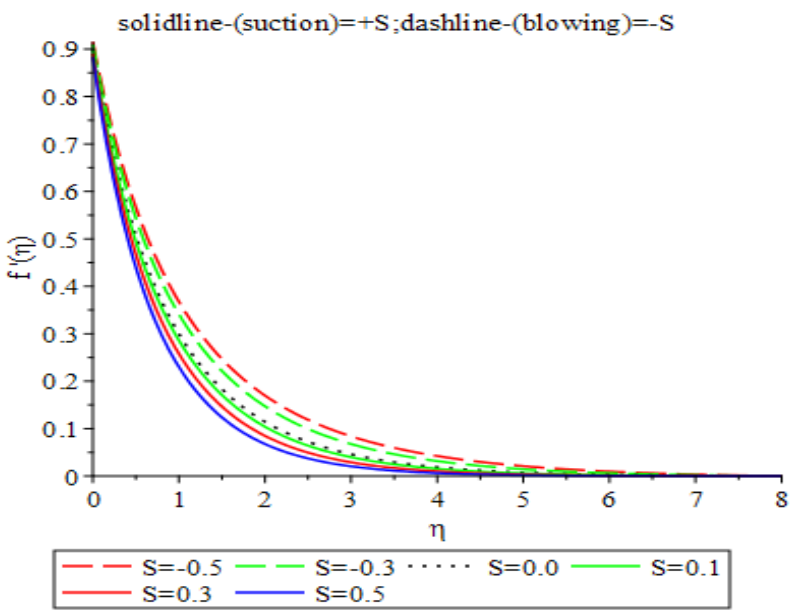

(a)

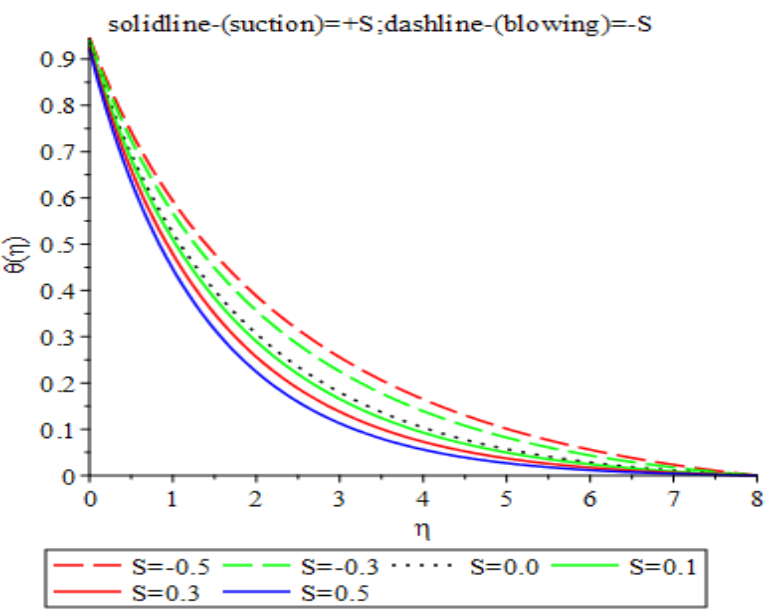

(b)

Figure 3. The effect of suction/blowing parameter vs velocity and temperature dimensionless

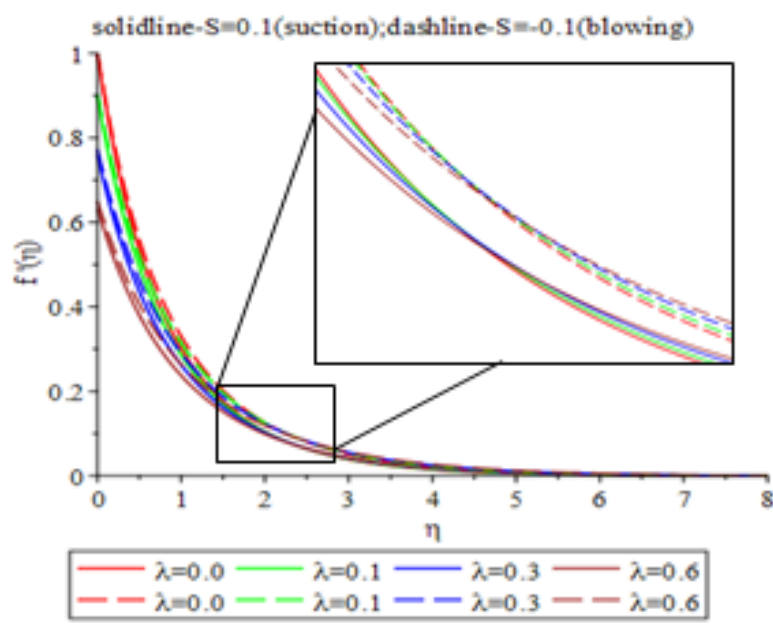

(a)

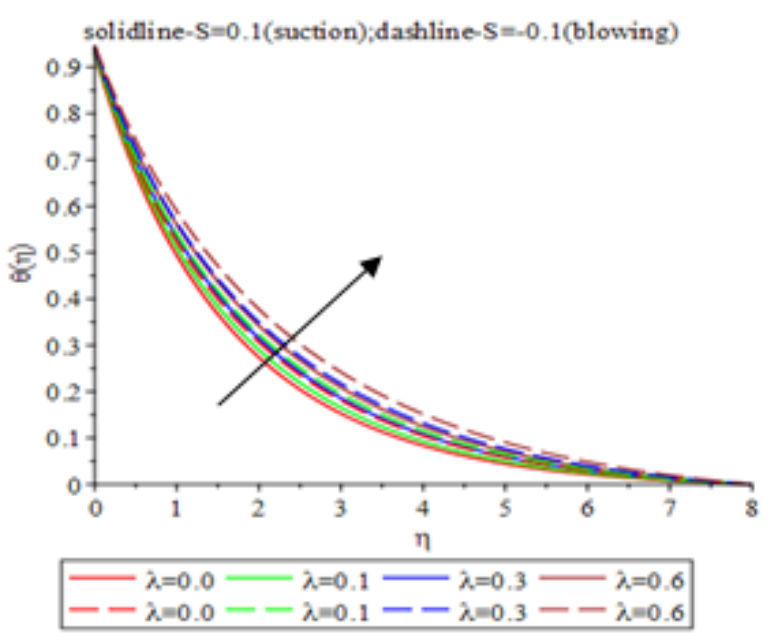

(b)

Figure 4. The effect of velocity slip parameter vs velocity and temperature dimensionless 
Fig.3(a) and Fig.3(b) investigate the suction/blowing parameter. It is obvious that the increment of suction/blowing parameter leads to decrease in the velocity and temperature as shown in fig.3 (a) and fig.3 (b) respectively. We assumed that the suction parameter $S=0.1$, $0.3,0.5$ and blowing parameter $\mathrm{S}=-0.3,-0.5$, such that $S=V_{o} \sqrt{2 l / U_{O}}$ where suction parameter, $\left.V_{o}\right\rangle 0$ and blowing $V_{o}\langle 0$. Fig.4 (a) and Fig.4 (b) exhibit the impact of velocity slip parameter against suction/ blowing cases. Fig.4 (a) shows that the increasing velocity slip parameter leads to decrease in the dimensionless velocity up to $\eta=2.277$ and then increases it. Whereas, the suction and blowing cases decreased and then increased at $\eta=2.342$ Moreover, the temperature profiles are increased for suction/blowing parameter with increased velocity slip parameter.

Fig. 5 shows the reaction of thermal slip, $\delta$ to temperature's effect for different value of suction/blowing parameter, $S$. In these cases, increase in thermal slip parameter leads to decrease in the temperature profile in suction and blowing parameters. Physically, increase in thermal slip parameter causes an increase in the rate of heat transfer with a decrease in temperature profiles.

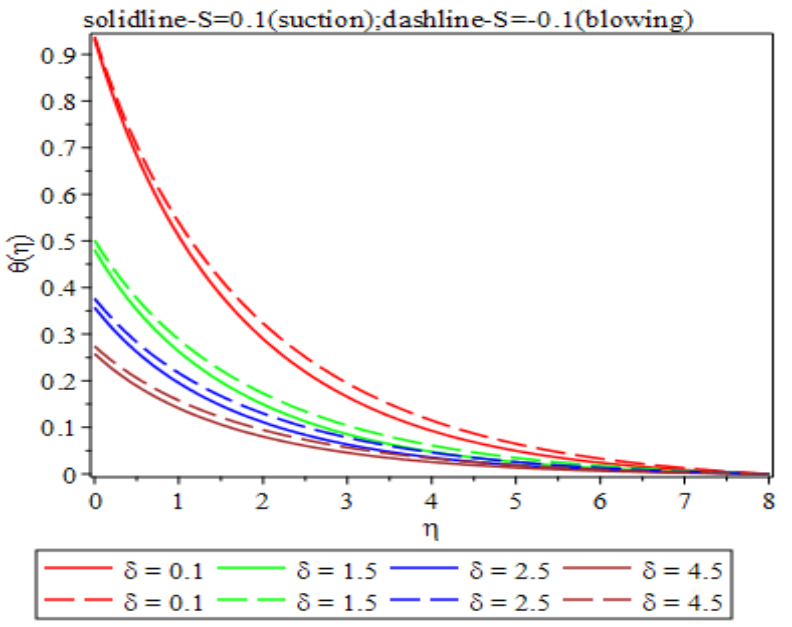

Figure 5. The effect of thermal slip parameter on temperature dimensionless

The impact of thermal radiation on the temperature profiles $\theta(0)$ is illustrated in fig. 6. It indicates that the temperature increases with the increasing thermal radiation parameters and this is in case of suction and blowing parameters. Moreover, fig. 6 shows the thickness of the higher boundary layer.

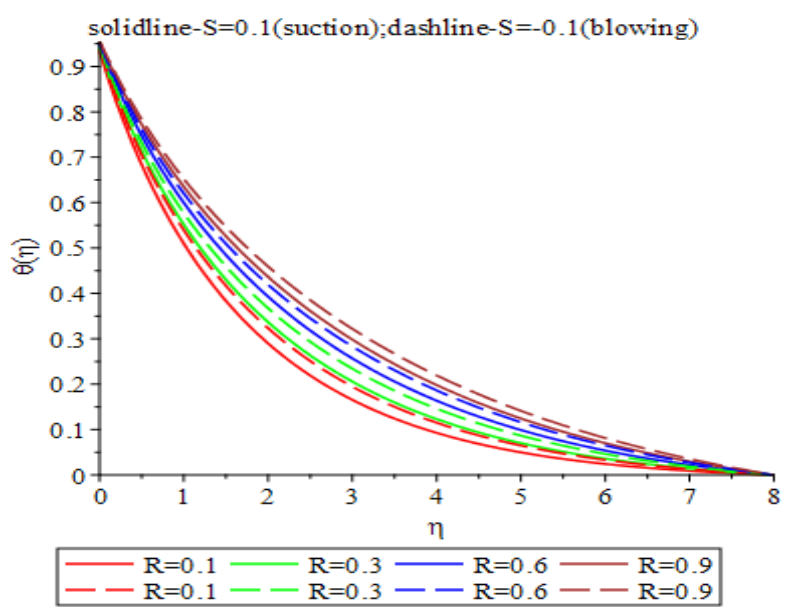

Figure 6. The effect of thermal radiation parameter on temperature dimensionless

\subsection{The Effect of Parameter on the Rate of Heat Transfer}

Fig. 7 signifies the effect of velocity slip parameter on the rate of heat transfer. It indicates that the increase in velocity slip parameter leads to decrease in the heat transfer especially in case of injection flow. Fig. 8 investigates the effect of thermal slip parameter on the rate of heat transfer with and without nanoparticle (copper) in case of suction flow. It is clear that increased thermal slip parameter leads to decrease in the heat transfer, but on the other hand, the nanofluid (copper-water) is improving the heat transfer compared to fluid (water)

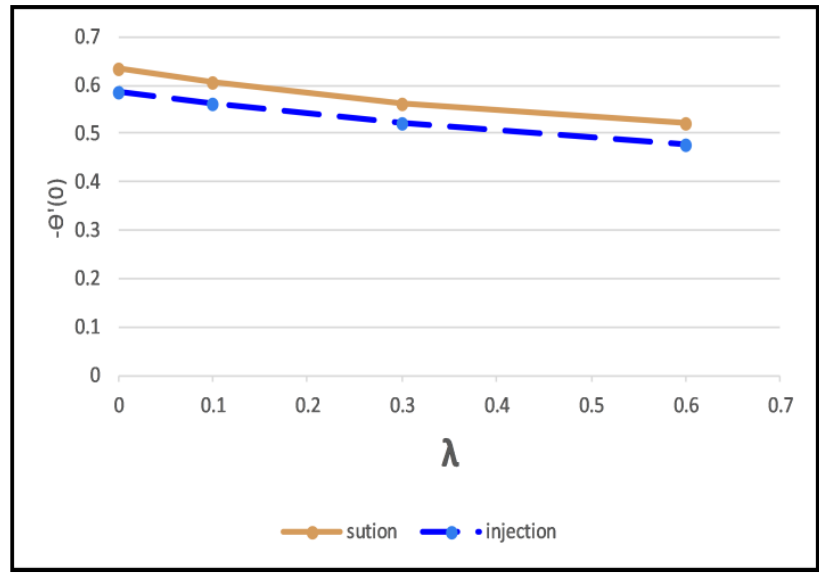

Figure 7. The effect of velocity slip parameter on the rate of heat transfer 


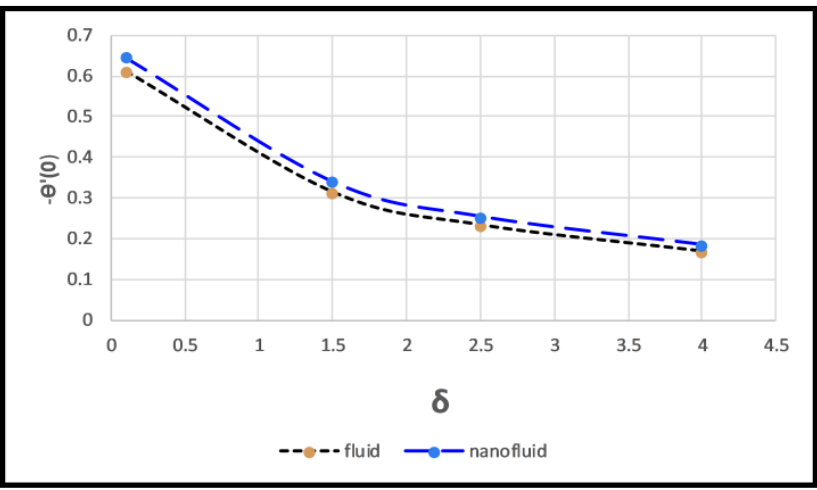

Figure 8. The effect of thermal slip parameter with and without nanoparticle (copper) on the rate of heat transfer in case of suction flow parameter

\section{Conclusions}

In this paper, the similarity transformation that depends on the similarity function is employed to propose analytic effect of MHD viscous of water-copper as nanofluid flows over an exponentially stretching sheet. Various values for the parameters were tested in this study such as magnetic field, radiation with velocity and thermal slip conditions on suction/blowing parameters and different reactions obtained for both velocity and temperature profiles are presented here. This was done both theoretically and numerically for clarity. In this work, the governing equations, momentum and energy were regenerated from Navier-Stockes equations that are partial differential equations into the nonlinear ODEs equation by using the similarity transformation that depends on the similarity function.

The velocity $f(\eta)$ and temperature $\theta(\eta)$ for different values of the parameter $S$ are displayed and analyzed. Various values of the parameters are handled and manipulated as the constant variables. Some of the reactions are concluded as follows:

i. Dimensionless velocity $f^{\prime}(\eta)$ decreases with increased magnetic field, suction/blowing, and thermal slip condition parameters

ii. The profiles of temperature $\theta(\eta)$ increase with the increasing magnetic field, velocity slip, and thermal radiation parameters

iii. For increased suction/blowing parameter, the temperature profile decreases.

iv. In cases of velocity slip parameter, the velocity dimensionless decreases firstly and then increases, and this happens because of the effect of the suction and blowing parameters

v. Finally, the effect of increased velocity and thermal slip parameters in general causes decrease in the heat transfer with base fluid, but in case of nanofluid this impact is lesser, meaning the nanofluid improves the heat transfer.

\section{Acknowledgements}

This research was supported by the university of Tun Hussein Onn Malaysia that the financial support under the grant tire 1 with number (H158).

\section{Nomenclature}

\begin{tabular}{|c|c|}
\hline$B(x)$ & Magnetic field \\
\hline$B_{o}$ & Constant depending of nature material \\
\hline$D_{O}$ & Initial value of thermal slip factor \\
\hline$U_{o}$ & Reference velocity \\
\hline$V_{o}$ & Initial strength of suction/injection \\
\hline$N_{O}$ & Initial value of velocity slip factor \\
\hline$k$ & Thermal conductivity \\
\hline$k^{*}$ & the absorption coefficient \\
\hline$M$ & Magnetic parameter \\
\hline$M H D$ & Magneto-hydrodynamic \\
\hline $\mathrm{m}$ & Empirical nanoparticle shape \\
\hline$c_{p}$ & Specific heat capacity \\
\hline$l$ & constant \\
\hline $\operatorname{Pr}$ & Prandtl number \\
\hline $\mathrm{S}$ & Suction/injection parameter \\
\hline$q_{r}$ & Radiation heat flux \\
\hline$T$ & temperature \\
\hline \multicolumn{2}{|l|}{$T_{o}$} \\
\hline$T_{\infty}$ & Free stream temperature \\
\hline$x, y$ & Axis direction \\
\hline$u, v$ & Velocity along $\mathrm{x}$ and $\mathrm{y}$ axis \\
\hline$f^{\prime}(\eta)$ & Velocity dimensionless \\
\hline$\theta(\eta)$ & temperature dimensionless \\
\hline
\end{tabular}

Greek symbols

$\alpha$

$\delta$

$\delta^{*}$

$\eta$

$\lambda$

$\mu$

$\rho$

$\sigma$

$\xi$

$v$

subscripts

$\infty$

$n f$
Thermal slip parameter

Stefan Boltzman constant

Similarity variable

Velocity slip parameter

Dynamic viscosity

density

Electrical conductivity

Nanoparticle volume fraction

Kinematic viscosity

Condition at infinity

nanofluid 


\section{REFERENCES}

[1] S. U. Choi and J. A. Eastman, "Enhancing thermal conductivity of fluids with nanoparticles," Argonne National Lab., IL (United States) 1995.

[2] A. Jamaludin, R. Nazar, and I. Pop, "Three-Dimensional Magnetohydrodynamic Mixed Convection Flow of Nanofluids over a Nonlinearly Permeable Stretching/Shrinking Sheet with Velocity and Thermal Slip," Applied Sciences, vol. 8, no. 7, 2018.

[3] W. Ibrahim and C. Zemedu, "Numerical solution of micropolar nanofluids with Soret, Dufor effects and multiple slip conditions," Journal of Physics Communications, 2019.

[4] R. K. Tiwari, M. K. J. I. J. o. h. Das, and M. transfer, "Heat transfer augmentation in a two-sided lid-driven differentially heated square cavity utilizing nanofluids," vol. 50, no. 9-10, pp. 2002-2018, 2007.

[5] J. J. J. o. h. t. Buongiorno, "Convective transport in nanofluids," vol. 128, no. 3, pp. 240-250, 2006.

[6] N. C. Roşca and I. Pop, "Unsteady boundary layer flow of a nanofluid past a moving surface in an external uniform free stream using Buongiorno's model," Computers \& Fluids, vol. 95, pp. 49-55, 2014.

[7] T. Hayat, S. Nadeem, and A. U. Khan, "Rotating flow of $\mathrm{Ag}-\mathrm{CuO} / \mathrm{H} 2 \mathrm{O}$ hybrid nanofluid with radiation and partial slip boundary effects," Eur Phys J E Soft Matter, vol. 41, no. 6, p. 75, Jun 142018.

[8] T. Hayat, A. Nassem, M. I. Khan, M. Farooq, and A. Al-Saedi, "Magnetohydrodynamic (MHD) flow of nanofluid with double stratification and slip conditions," Physics and Chemistry of Liquids, vol. 56, no. 2, pp. 189-208, 2017.

[9] J. Zhu, P. Chu, and J. Sui, "Exact Analytical Nanofluid Flow and Heat Transfer Involving Asymmetric Wall Heat Fluxes with Nonlinear Velocity Slip," Mathematical Problems in Engineering, vol. 2018, pp. 1-12, 2018.

[10] Y. S. Daniel, Z. A. Aziz, Z. Ismail, and F. Salah, "Effects of slip and convective conditions on MHD flow of nanofluid over a porous nonlinear stretching/shrinking sheet," Australian Journal of Mechanical Engineering, pp. 1-17, 2017.

[11] R. Dhanai, P. Rana, and L. Kumar, "MHD mixed convection nanofluid flow and heat transfer over an inclined cylinder due to velocity and thermal slip effects: Buongiorno's model," Powder Technology, vol. 288, pp. 140-150, 2016.

[12] M. Khan and Hashim, "Effects of multiple slip on flow of magneto-Carreau fluid along wedge with chemically reactive species," Neural Computing and Applications, vol. 30, no. 7, pp. 2191-2203, 2016.

[13] F. Mabood, G. Lorenzini, N. Pochai, and S. Shateyi,
"Homotopy Analysis Method for Radiation and Hydrodynamic-Thermal Slips Effects on MHD Flow and Heat Transfer Impinging on Stretching Sheet," Defect and Diffusion Forum, vol. 388, pp. 317-327, 2018.

[14] B. Mahanthesh, B. J. Gireesha, R. S. R. Gorla, and O. D. Makinde, "Magnetohydrodynamic three-dimensional flow of nanofluids with slip and thermal radiation over a nonlinear stretching sheet: a numerical study," Neural Computing and Applications, vol. 30, no. 5, pp. 1557-1567, 2016.

[15] W. Ibrahim and B. Shankar, "MHD boundary layer flow and heat transfer of a nanofluid past a permeable stretching sheet with velocity, thermal and solutal slip boundary conditions," Computers \& Fluids, vol. 75, pp. 1-10, 2013.

[16] S. Ahmad, M. Yousaf, A. Khan, and G. Zaman, "Magnetohydrodynamic fluid flow and heat transfer over a shrinking sheet under the influence of thermal slip," Heliyon, vol. 4, no. 10, p. e00828, Oct 2018.

[17] M. Usman, F. A. Soomro, R. Ul Haq, W. Wang, and O. Defterli, "Thermal and velocity slip effects on Casson nanofluid flow over an inclined permeable stretching cylinder via collocation method," International Journal of Heat and Mass Transfer, vol. 122, pp. 1255-1263, 2018.

[18] D. Ramya, R. S. Raju, J. A. Rao, and A. J. Chamkha, "Effects of velocity and thermal wall slip on magnetohydrodynamics (MHD) boundary layer viscous flow and heat transfer of a nanofluid over a non-linearly-stretching sheet: a numerical study," Propulsion and Power Research, vol. 7, no. 2, pp. 182-195, 2018.

[19] R. Ul Haq, S. Nadeem, Z. Hayat Khan, and N. Sher Akbar, "Thermal radiation and slip effects on MHD stagnation point flow of nanofluid over a stretching sheet," Physica E: Low-dimensional Systems and Nanostructures, vol. 65, pp. 17-23, 2015.

[20] N. Nagendra, C. H. Amanulla, M. S. Reddy, and V. R. Prasad, "Hydromagnetic Flow of Heat and Mass Transfer in a Nano Williamson Fluid Past a Vertical Plate With Thermal and Momentum Slip Effects: Numerical Study," Nonlinear Engineering, vol. 8, no. 1, pp. 127-144, 2019.

[21] S. Mukhopadhyay and H. I. Andersson, "Effects of slip and heat transfer analysis of flow over an unsteady stretching surface," Heat and Mass Transfer, vol. 45, no. 11, pp. 1447-1452, 2009.

[22] H. R. Jasim, M. Mohamad, M. M. Fayyadh, A. T. Alomari, and A. A. Abdulridha, "Numerical Analysis of Mass Transfer in MHD Nanoparticle Based Crude Oil Flow on a Flat Plate under Various Slip Condition," in Journal of Physics: Conference Series, 2019, vol. 1366, no. 1, p. 012042: IOP Publishing.

[23] L. A. Dombrovsky, S. Dembele, and J. X. Wen, "Shielding of fire radiation with the use of multi-layered water mist curtains: preliminary estimates," Computational Thermal Sciences: An International Journal, vol. 8, no. 4, 2016.

[24] A. Izham, A. Ramli, W. S. W. Hassan, H. Idris, and N. Basri, "Terrestrial Gamma Radiation Dose Rate of West Sarawak," in EPJ Web of Conferences, 2017, vol. 156, p. 00006: EDP Sciences.

[25] S. Hassani, R. Saidur, S. Mekhilef, and A. Hepbasli, "A new 
correlation for predicting the thermal conductivity of nanofluids; using dimensional analysis," International Journal of Heat and Mass Transfer, vol. 90, pp. 121-130, 2015.

[26] N. Sandeep, C. Sulochana, and B. R. Kumar, "Unsteady MHD radiative flow and heat transfer of a dusty nanofluid over an exponentially stretching surface," Engineering science and technology, an international journal, vol. 19, no. 1, pp. 227-240, 2016.

[27] S. Qayyum, T. Hayat, and A. Alsaedi, "Chemical reaction and heat generation/absorption aspects in MHD nonlinear convective flow of third grade nanofluid over a nonlinear stretching sheet with variable thickness," Results in physics, vol. 7, pp. 2752-2761, 2017.

[28] R.-D. Ene and V. Marinca, "Approximate solutions for steady boundary layer MHD viscous flow and radiative heat transfer over an exponentially porous stretching sheet," Applied Mathematics and Computation, vol. 269, pp. 389-401, 2015

[29] M. M. Fayyadh, R. Roslan, R. Kandasamy, and I. R. Ali, "Thermal Energy on Water and Oil placed Squeezed Carreau Nanofluids Flow."

[30] M. M. Fayyadh, R. Roslan, R. Kandasamy, I. R. Ali, and N. A. Hussein, "Effect of Biot Number on Convective Heat Transfer of Darcy-Forchheimer Nanofluid Flow over Stretched Zero Mass Flux Surface in the Presence of Magnetic Field," 2019.

[31] A. ISHAK, "MHD Boundary Layer Flow Due to an Exponentially Stretching Sheet with Radiation Effect," Sains Malaysiana, vol. 40, pp. 391-395, 2011.

[32] S. Mukhopadhyay, "Slip effects on MHD boundary layer flow over an exponentially stretching sheet with suction/blowing and thermal radiation," Ain Shams Engineering Journal, vol. 4, no. 3, pp. 485-491, 2013. 